\title{
Perceptions of Preservice Teachers about Adaptive Learning Programs in K-8 Mathematics Education
}

\author{
Kevin Smith \\ Dakota State University, United States
}

Received: 14.08 .2017

Accepted: 08.03.2018

Published: 13.04.2018

\begin{abstract}
Adaptive learning programs are frequently used in the K-8 mathematics classroom. These programs provide instruction to students at the appropriate level of difficulty by presenting content, providing feedback, and allowing students to master skills before progressing. The purpose of the study was to seek to interpret how preservice teachers' experiences influence their perceptions and plans to integrate adaptive learning programs in their future K-8 mathematics classroom. This was a qualitative study with 17 participants who were enrolled in an undergraduate teacher education program. Data was collected and analyzed from archived journals the participants completed as a part of their K-8 Math Methods course, a survey, and semi-structured interviews. The findings from this study indicate that the participating preservice teachers perceive adaptive learning programs to be beneficial for students, and they recognize they have many decisions to make regarding what adaptive learning programs are used and how they are integrated into the classroom. The study also found that the instruction the preservice teachers received in their K-8 Math Methods course played a critical role in making them aware of the features available and myriad of options available in adaptive learning programs.
\end{abstract}

Keywords: Preservice teacher education; Mathematics education; Adaptive learning systems; Perceptions for technology; Experiences with adaptive learning programs

\section{Introduction}

In kindergarten through grade 12 mathematics education, technology is viewed as an integral part of instruction. There is evidence to support the positive impact technology has on mathematics achievement (Cheung \& Slavin, 2013; Eyyam \& Yaratan, 2014; Ojose, 2009; Schacter, 1999; Weaver, 2000; Zhang, Trussell, Gallegos, \& Asam, 2015). In a meta-analysis of 74 studies on the effectiveness of educational technology on mathematics achievement in the K-12 classroom, Cheung and Slavin (2013) found that technology had a positive, though moderate, effect. Additionally, leading organizations that provide guidance on K-12 mathematics education such as the National Council of Teachers of Mathematics (NCTM), the Association of Mathematics Teacher Educators (AMTE), and the National Mathematics Advisory Panel have provided directives for K-12 mathematics teachers on the importance of integrating technology in the classroom (AMTE, 2015; National Mathematics Advisory Panel, 2008; NCTM, 2014). NCTM's Principles to Actions: Ensuring Mathematical Success for All publication states, "An excellent mathematics program integrates the use of mathematical tools and technology as essential resources to help students learn and make sense of mathematical ideas, reason mathematically, and communicate their mathematical thinking" (NCTM, 2014, p. 78). 
In the context of K-12 mathematics education, there are a number of different types of technology commonly used. Calculators, interactive whiteboards, computer algebra systems, dynamic geometry environments, and adaptive learning programs are some of the technologies used in K-12 mathematics classrooms (Brahier, 2013; NCTM, 2014; Ozel, Yetkiner, \& Capraro, 2008). This study focused on adaptive learning programs in grades K-8.

For the purposes of this study, adaptive learning programs are defined as technology-based programs that adapt to the learner based on their responses and how they interact with the program (Hanover Research, 2014; Johnson, Adams Becker, Estrada, \& Freeman, 2015; Klinkenberg, Straatemeier, \& Van Der Maas, 2011; Oxman \& Wong, 2014). Adaptive learning programs provide students with assessments, instructional content, hints, and feedback on their progress as they learn new mathematics skills or reinforce existing skills. ALEKS, DreamBox Learning, IXL Math, Khan Academy, and TenMarks are examples of adaptive learning programs used in K-8 mathematics classrooms.

As with other technologies used in $\mathrm{K}-8$ learning environments, teacher training is important for effective implementation. According to the U.S. Department of Education's 2016 Educational Technology Plan created by the Office of Educational Technology, preservice teachers should be prepared to "use technology in meaningful ways" (p. 32). This notion is further emphasized by the Council for the Accreditation of Educator Preparation Standards (CAEP, 2013), which is an accrediting body for teacher education programs. The CAEP Standards indicate that preservice teachers should be able to "apply technology standards as they design, implement and assess learning experiences to engage students and improve learning; and enrich professional practice" (CAEP, 2013). Research shows when teachers are prepared to implement technology effectively, student performance improves. Unfortunately, not all teachers are prepared to implement technology tools such as adaptive learning programs effectively (Hennessy, Ruthven, \& Brindley, 2005; U.S. Department of Education, 2016; Wenglinsky, 1998). There is also a lack of research that specifically looks at preparing preservice teachers to use adaptive learning programs in the K-8 mathematics classroom.

The purpose of this qualitative study was to explore the perceptions of preservice teachers and their plans for implementing adaptive learning programs in their future classroom. One of the first steps in preparing teachers to use technology is to understand their perceptions about the technology. According to Imbimbo (2003), "perceptions provide useful information on areas where teachers feel most knowledgeable and areas where they feel most lacking" (p. 7). Sutton (2011) adds that by understanding perceptions of preservice teachers, there is "a better chance of providing training that will positively influence their self-efficacy, and, thus, their teaching practices" (p. 40). The goal of this study was to learn about perceptions and the influence of experiences to begin to lay the ground work for developing teacher education programs that effectively prepare preservice teachers to implement adaptive learning programs in their K-8 mathematics classroom.

This study sought to gather information to understand the preservice teachers' perceptions of adaptive learning programs and their plans for implementing these programs in their future classroom by conducting a survey, analyzing archived journals, and conducting semi-structured interviews with preservice teachers that have completed a K-8 Math Methods course. This study was guided by two research questions:

1. What are preservice teachers' perceptions of using adaptive learning programs in the K8 mathematics classroom? 
2. How do preservice teachers' experiences influence their perceptions and plans to integrate adaptive learning programs in their future classroom?

\section{Literature Review}

\section{Why Adaptive Learning Programs?}

According to the NMC Horizon Report (2015) adaptive learning and components of adaptive learning, such as learning analytics and personalized instruction, are identified as key trends in educational technology. The ConnectED initiative that was launched in 2013 by the U.S. government specifically aims to "empower students through individualized learning and rich, digital content" (ConnectED, 2013, para. 1). These are key tenets of the adaptive learning programs used by many schools. The adaptive learning programs used in schools today have evolved over time and continue to evolve based on research and technology innovation.

The features available in adaptive learning programs have promise for $\mathrm{K}-8$ mathematics teachers looking to enhance student learning. Providing immediate feedback to students, requiring students to master skills before advancing, and collecting data on student activities are a few of the benefits associated with adaptive learning programs (Nguyen et al., 2006). Recent studies have shown students' performance improves when adaptive learning programs are used specifically in the mathematics classroom (Beal, Cohen, \& Woolf, 2010; Bochniak, 2014; Cheung \& Slavin, 2013; Liao, 2007). Additionally, studies have shown that students have positive attitudes about using adaptive learning programs (Kulik, 2013; Nguyen, Hsieh, \& Allen, 2006; Pane, Griffin, McCaffrey, \& Karam, 2013). The features and benefits of adaptive learning programs make them a popular technology for K-8 mathematics classrooms.

\section{Teacher Training}

Having the right technology tool is one thing. Understanding how to use it effectively is another. There is much literature on the importance of training teachers to integrate technology effectively (Chai, Hwee, Koh, \& Tsai, 2010; Davis et al.,2009; Kim, Kim, Lee, Spector, \& DeMeester, 2013; Lee \& Hollebrands, 2008; Niess, 2005; Ozel et al., 2008). Additionally, several reports and educational standards highlight the importance of training teachers to utilize technology (AMTE, 2015; CAEP, 2013; ISTE Standards for Administrators, 2016; National Education Technology Plan, 2016). It is clear from the literature that training teachers to integrate technology effectively is important.

\section{Preservice Teachers}

One particular area of emphasis with training teachers to use technology is in teacher education programs. Research indicates that teacher education programs have a major influence on how teachers ultimately end up using technology in their classrooms (Tondeura et al., 2012). According to the US Department of Education's 2016 National Education Technology plan, "Institutions responsible for pre-service and in-service professional development for educators should focus explicitly on ensuring all educators are capable of selecting, evaluating, and using appropriate technologies and resources to create experiences that advance student engagement and learning" (p. 25). The literature also indicates that preservice teachers are not 
adequately prepared to use technology (Albee, 2003; National Education Technology Plan, 2016; Niess, 2005) thus it is important to continue to research ways to improve teacher education programs regarding technology integration.

\section{Beliefs and Perceptions}

One particular area associated with developing effective technology training for preservice teachers has to do with understanding their beliefs and perceptions about technology. The beliefs and perceptions of preservice teachers about technology has an impact on how likely they are to implement it in their classroom (Kim et al., 2013; Sutton, 2011). According to Ertmer (2005), it is "impossible to overestimate the influence of teachers' beliefs" (p. 36) as you consider how to effectively train preservice teachers to utilize technology. Having an awareness of the beliefs and perceptions of preservice teachers about technology has the potential to provide valuable information for providing effective teaching training. Unfortunately, there is very little research that specifically addresses the perceptions of preservice teachers about adaptive learning programs in the $\mathrm{K}-8$ mathematics classroom.

\section{Summary}

Based on the literature, we know that adaptive learning programs are a growing technology trend in education. We also know, based on the literature, that training teachers, especially preservice teachers, to use technology effectively is important. One of the first steps in developing effective training for preservice teachers is understanding their perceptions (Ertmer, 2005). This research study looks at the perceptions of preservice teachers and how their experiences influence these perceptions as well as their plans for using adaptive learning programs. If we can gain a better understanding of preservice teachers' perceptions regarding this particular popular technology, we can begin to take steps toward improving teacher education programs.

\section{Methodology}

\section{Participants}

Participants for this study were students from one section of a K-8 Math Methods course that was taught at a small, public university in the Upper Midwest of the United States. This particular section had 18 students enrolled and 17 of those students agreed to participate in the study. Of the 17 students that participated, 8 indicated they are pursuing an Elementary Education degree and 9 are pursuing an Elementary Education/Special Education composite degree. All of the participants had been admitted to the Teacher Education program and were juniors or seniors with grade point averages ranging from 2.94 to 4.0. The participants ranged in age from 21 to 41 with 13 females and 4 males.

The students chosen to participate were selected based on convenience. Convenience sampling is used based on time, money, location, and availability (Merriam, 2009). For the students that agreed to participate, their involvement consisted of completing a brief survey, and having their archived journals from an instructional unit on adaptive learning programs during their K-8 Math Methods course analyzed. 
A subset of the 17 participants was invited to participate in semi-structured interviews as well. To select participants for these interviews, purposeful sampling was used. Purposeful sampling involves selecting information-rich cases that lend themselves to helping understand what is being studied (Patton, 2015). The specific type of purposeful sampling that was used was criterion sampling. The criteria for selecting participants for the semi-structured interviews was based on the following:

a) completed response for each of the journal questions,

b) evidence of self-reflection in their journal responses (e.g. responses are more than just a few words and provide information on specific experiences and attitudes about adaptive learning programs),

c) ability to provide in-depth answers based on what the researcher knows about them as students from the K-8 Math Methods class (i.e. this was based on the researcher's experience working with the students in class and their ability to engage in meaningful class discussions),

d) multiple experiences using adaptive learning programs.

Seven of the 17 participants were initially identified to participate in the interview portion of the study based on the sampling strategy. After conducting the fifth interview, it was determined that no new information was emerging. A point of saturation was reached in the data collected, and no further interviews were conducted.

\section{Data Collection Instruments}

Multiple instruments were used to collect data for this study. A survey, documents, and interviews were used to answer the research questions. Utilizing multiple instruments to collect data is a characteristic of qualitative research (Creswell, 2009). This section will provide details on the instruments that were used.

\section{Demographic and Experience Survey}

An 18-question survey was completed by the 17 participants at the beginning of the study. This brief survey was used to collect demographic data as well as information on participants' prior experience with technology and adaptive learning programs. The data from the survey was primarily used to learn about participants' experiences using adaptive learning programs and to assist in selecting participants for the semi-structured interviews.

\section{Archived Journals}

As a part of the 3-day instructional unit on adaptive learning programs, participants completed journals following each of the three class periods. Participants received specific open-ended questions for each journal. The questions were tied to the lesson objectives and were designed to stimulate prior learning and make connections with newly acquired information. Each journal entry contained one to three paragraphs of information provided by the participant. There was a total of 51 journals, three journal entries for each student, that were analyzed. 


\section{Semi-structured Interviews}

Individual interviews were conducted with 5 of the 17 participants. Semi-structured interviews were used as the interview format. Semi-structured interviews allow for a more flexible form of questioning when compared to a structured interview format (Merriam, 2009). An interview protocol was used to conduct the interviews and ensure that the questions were aligned to the research questions.

Once the interviews were recorded, they were transcribed in their entirety. The transcribed interview data was collected in a Word doc and imported into the qualitative analysis web application, SaturateApp, for analysis.

\section{Data Analysis}

The goal with a basic qualitative study "is to understand how people make sense of their lives and experiences" (Merriam \& Tisdell, 2016, p. 24). To do this large amounts of data must be collected, organized, and analyzed (Merriam, 2009). For this study, data from 17 surveys, 51 archived journals, and 5 semi-structured interviews was collected, organized, and analyzed using a thematic analysis approach (Braun \& Clark, 2006).

The analysis was guided by a three-stage thematic analysis approach outlined by King and Horrocks (2010). This three-stage approach involves doing descriptive coding, interpretive coding, and then identifying overarching themes.

\section{Stage 1 - Descriptive Coding}

The first stage of analysis involved adding descriptive codes to all of the data. The codes were added using the qualitative analysis web application, SaturateApp. Figure 1 shows a screenshot of a portion of the data with descriptive codes assigned.

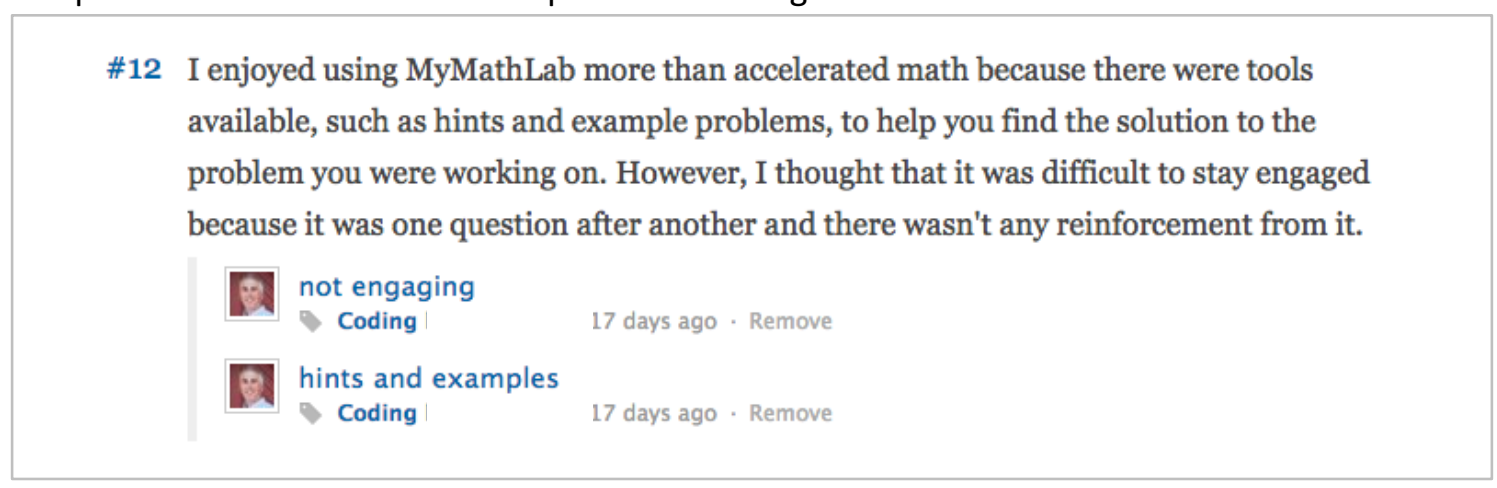

Figure 1. Screenshot of SaturateApp with Descriptive Codes

Once descriptive codes had been added to the first participants' journals, the researcher proceeded to the second participants' journal adding codes in a similar fashion. As each journal was completed, the researcher revisited the entire list of descriptive codes and refined the codes by combining, removing, and editing them. The researcher went through multiple iterations of 
this process to make sure all of the relevant information was identified. Once all of the journals had been coded, the interview transcripts were coded using the same process.

\section{Stage 2 - Interpretive Coding}

For the interpretive coding stage, the researcher sought to interpret the descriptive codes that were identified and group them together. Similar to the first stage, this was an iterative process in which codes were revised as information emerged. In this stage, the researcher focused on looking at the descriptive codes from the first stage and then began to interpret their meaning.

\section{Stage 3 - Overarching Themes}

The last stage of the analysis involved creating overarching themes based on the interpretive codes. To provide more flexibility in the analysis process, all of the data was exported from the SaturateApp and imported into a Google Sheet. Using the Google Sheet the researcher was able to sort by the interpretive code and descriptive code columns to look for themes.

\section{Trustworthiness}

To ensure the quality of a qualitative study, researchers must take several things into account. According to Lincoln and Guba (1985), credibility and dependability are two key criteria that must be considered in qualitative research. Credibility has to do with making sure the findings from the study actually represent reality. Dependability has to do with making sure the study is described in rich detail to account for changing conditions. Several things were done as a part of this study to address these criteria.

\section{Credibility and Dependability}

To address credibility and dependability, three common strategies were utilized associated with qualitative research: triangulation, member checking, and rich descriptions. Triangulation, as it applies to this study, involved using multiple sources of data. This strategy has the potential to help give the researcher a deeper understanding of the perceptions of the participants (Denzin, 1978). Data from the surveys, archived journals, and semi-structured interviews was compared to look for consistent themes. Comparing data occurred during data analysis.

Member checking was the second strategy. Member checking is another common strategy used to help ensure validity in qualitative studies (Marshall \& Rossman, 2016). Member checking involves soliciting feedback from participants on your initial findings (Merriam, 2009). To implement member checking in this study, the preliminary analysis of the interview data and archived journals was shared with the participants. They were asked if the researcher interpreted things correctly and they were given an opportunity to provide feedback.

Finally, rich descriptions were used to describe the study. Providing rich descriptions involves providing specific information on all of the details of the study (Merriam, 2009). Rich descriptions were provided to describe the participants in the study, the setting in which it 
occurred, the instruction the participants received, and details on how the data was collected and analyzed.

\section{Findings}

Several themes emerged based on the data analysis. Three themes emerged that align to the first research question. For the second research question, information on the participants' experiences and two themes emerged. Below are the details on those themes.

\section{Research Question 1}

The first research question in this study was: What are preservice teachers' perceptions of using adaptive learning programs in the K-8 mathematics classroom? The primary purpose in researching this question was to look specifically at the perceptions of the participants regarding adaptive learning programs.

\section{Theme 1 - Beneficial for Students}

The first theme that emerged relating to perceptions was that the participants perceive adaptive learning programs as being beneficial for students. Participants identified a number of positive program features inherent in adaptive learning programs. Specific terms used by many participants to describe these positive program features included "self-paced," "immediate feedback," and "fun and engaging." There were also commonalities in how they described the overall learning experience for students. Items mentioned included words and phrases about mastery learning, no time pressure, and offering different instructional approaches for students. The following quotes were associated with these positive perceptions from both the journal and interview data:

Ava (Journal): I do think these are a valuable tool in the classroom because they do a great job of differentiating instruction for each student. It also helps provide the teacher with data about each student and the class as a whole. It also provides the students with instant feedback.

Karsyn (Journal): The programs are self-paced and have a help section that can help you work through the problem. In some cases, I only needed to know how to do one step correctly and these programs allow you to look at the specific step.

Jessie (Journal): I think that these programs are valuable because they give instant feedback, students can work at their own pace, and they integrate technology into the lesson.

The data collected in the survey also supported this theme as well. More than $94 \%$ of the participants responded with "Agree" or "Strongly Agree" when asked about whether adaptive learning programs should be used in the K-8 mathematics classroom (Table 1). 
Table 1. Demographic \& Experience Survey - Item 17

\begin{tabular}{lr}
\hline Item 17. I think adaptive learning programs should be used in the K-8 mathematics \\
classroom. & \# (\%) of Participants \\
\hline Response & $4(23.53 \%)$ \\
\hline Strongly agree & $12(70.59 \%)$ \\
Agree & $1(5.88 \%)$ \\
Neither Agree nor Disagree & $0(0 \%)$ \\
Disagree & $0(0 \%)$ \\
Strongly Disagree & 17 \\
Total & \\
\hline
\end{tabular}

Additionally, more than $58 \%$ of the participants responded with "Definitely" or "Very Probably" when asked about whether they plan to use an adaptive learning program in their future K-8 mathematics classroom (Table 2).

Table 2. Demographic \& Experience Survey - Item 18

\begin{tabular}{lr}
\hline $\begin{array}{l}\text { Item } 18 . \text { I am planning to use an adaptive learning program in my future K-8 mathematics } \\
\text { classroom. }\end{array}$ \\
\hline Response & \# (\%) of Participants \\
\hline Definitely & $3(17.65 \%)$ \\
Very Probably & $7(41.18 \%)$ \\
Probably & $6(35.29 \%)$ \\
Possibly & $1(5.88 \%)$ \\
Probably Not & $0(0 \%)$ \\
Definitely Not & $0(0 \%)$ \\
Total & 17 \\
\end{tabular}

Despite the overwhelming number of positive perceptions of adaptive learning programs for students, a few participants did recognize drawbacks of these programs that are worth noting. The two most common concerns expressed by participates related to negative experiences they had using particular programs and potential technology barriers. Participants mentioned items relating to negative learning experiences such as not receiving immediate feedback and the programs not being very engaging. In terms of technology barriers, the participants noted that some programs may be challenging for very young students and Internet access could be a challenge for some students. Overall, however, participants perceive adaptive learning programs to be beneficial to students.

\section{Theme 2-Role of the Teacher Matters}

The second theme that emerged relating to the first research question was: The role of the teacher is important in determining how adaptive learning programs are used in classrooms. Participants had fairly strong feelings about the role the teacher should play when using an adaptive learning program. The data indicated that participants believe that teachers play an important role in four main areas relating to adaptive learning programs: 1) classroom environment; 2) curriculum alignment; 3) teacher support; and 4) program selection. 
In terms of classroom environment, participants believe it is the role of the teacher to control the classroom environment. Classroom environment in this context refers to things such as classroom management, motivation of the students, time pressure placed on students, establishing goals for students, and the importance of establishing routines for using the programs. Below are specific examples of what the participants said about classroom environment:

Brittany (Journal): I think they would be more effective if there was potentially a reward program or milestone rewards to keep the students motivated and active in their learning.

Christina (Journal): I really enjoyed that there was a set goal that we were working for, but it wasn't a timed goal. This makes is so students don't feel so rushed.

Participants noted the importance of making sure the adaptive learning program is aligned to the curriculum of the mathematics course that is being used in. In several cases, participants viewed the implementation as not being done in a meaningful way.

Bridget (Interview): I think it was just kind of how they used it, it was just like doing something to do something. It wasn't really meeting the objectives.

Brittany (Journal): We used Accelerated Math in addition to what we were learning in the classroom. I remember lots of times the content we covered in class did not line up with what was on our Accelerated Math problems for that day.

The amount of support and guidance provided by the classroom teacher that was implementing the adaptive learning program was a consistent theme amongst participants. Almost all of the participants had a common experience of using an adaptive learning program in one of their college courses. This experience involved using an adaptive learning program as the primary curriculum for an online math course. Almost all of the students had negative perceptions about using an adaptive learning program in this fashion. The primary reason noted had to do with the lack of teacher support or involvement.

Despite these negative experiences, the $94 \%$ of participants indicated they plan to use adaptive learning programs in their future classrooms. They specifically mentioned the way in which they plan to implement the programs. The implementation approaches are detailed in the next theme, but it is important to note that the preferred implementation approaches involve increased levels of teacher support. The participants perceive the level of teacher support as an important role of the teacher.

Finally, program selection has to do with how teachers select the adaptive learning program to use in their classroom. Overall, the participants did not have very much experience working with the wide range of programs available. Most of the students had worked with two or three different adaptive learning programs during the various experiences. Despite their limited experiences, they did recognize that teachers have decisions to make about which programs to actually use and implement in their classrooms. These decisions have to do with their confidence level in using the program, ease of use, and costs. 


\section{Theme 3 - Implement as a Supplement}

The third theme that emerged relating to the first research question was that participants believe that adaptive learning programs should be implemented as a supplement to classroom instruction. This theme is supported by two primary sub-themes. First, the participants had experiences using adaptive learning programs with different implementation methods. Second, the participants indicated consistent support for a particular implementation plan in terms of how they plan to use adaptive learning programs as teachers.

Implementation methods in this context refer to how adaptive learning programs are used in classrooms. Participants had experiences with several different implementation methods. For the participants that had experience using an adaptive learning program in their K-12 mathematics classroom, most of the implementation methods involved using the programs for extra practice, review, or remediation. There were only two students that indicated the adaptive learning program was implemented as the primary curriculum for the course.

All of the participants had experiences using adaptive learning programs in their college courses, and they had experiences with multiple implementation methods in those courses. The participants' perceptions of those implementation methods were consistent across the majority of participants. They had negative feelings about using adaptive learning programs as the primary curriculum, and they had more positive feelings about adaptive learning programs when they were used for review or extra practice. Based on what participants noted about implementation methods, they believe that adaptive learning programs should be implemented as a supplement to classroom instruction.

The second sub-theme deals with the participants' specific plans for implementing adaptive learning programs in their future classroom. As indicated earlier, the survey indicated that $94 \%$ of participants think adaptive learning programs should be used in the K-8 mathematics classroom, and they plan to implement an adaptive learning program in their future $\mathrm{K}-8$ mathematics classroom (see Table 1 and Table 2). Several questions in the journals and in the interviews dealt specifically with how they plan to use adaptive learning programs as teachers. Nearly all of the participants indicated that they believe adaptive learning programs should be implemented as a supplement. The following excerpts are examples of those beliefs:

Bradley (Journal): I think it will be something that I use for students who are struggling in a particular area to go back and work on. If the rest of the class is ready to move on it may be a good way to keep moving forward while giving a particular student a chance to go back and get a better grasp for some of the concepts.

Brock (Journal): Depending on the school's arrangement with adaptive learning, I would like to implement it as supplemental opportunities from teacher directed learning.

\section{Research Question 2}

The second research question in this study was: How do preservice teachers' experiences influence their perceptions and plans to integrate adaptive learning programs in their future classroom? The primary purpose in researching this question was to look specifically at the experiences of the participants that relate to using, learning about, and observing adaptive learning programs in the mathematics classroom. While the first research question focused on 
the perceptions themselves, this research question and the themes that emerged from the data focuses on the various experiences and the influence of those experiences.

\section{Experiences}

Data from the survey, archived journals, and semi-structured interviews was used to determine what experiences the participants have had with adaptive learning programs in the mathematics classroom. Four distinct experiences were identified in the data:

Experience 1: K-12 student - Participants used adaptive learning programs in their K-12 classrooms.

Experience 2: College student - Participants used adaptive learning programs in their college mathematics courses.

Experience 3: Instruction - Participants received instruction in their K-8 Math Methods course.

Experience 4: Classroom field experiences - Participants observed adaptive learning programs being used in $\mathrm{K}-8$ classrooms during their field experiences.

Figure 2 provides a visual to help clarify the frequency and how long ago each experience occurred.

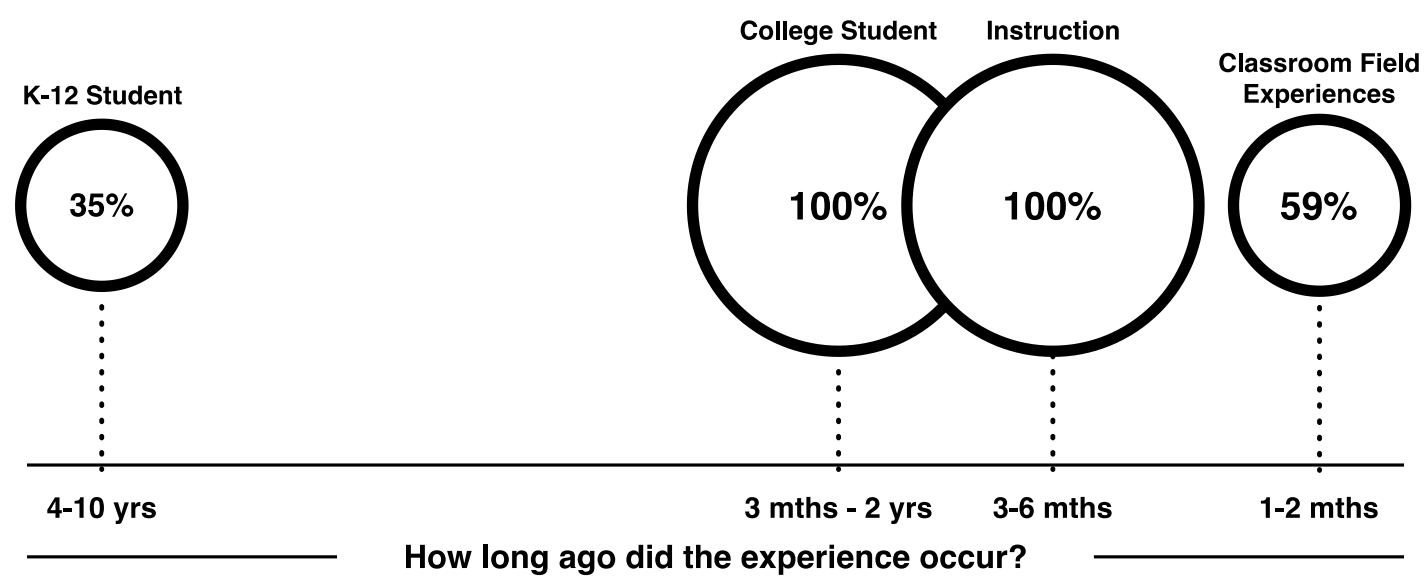

Figure 2. Visual Display of the Four Experiences Participants Have Had with Adaptive Learning Programs.

Note: The size of each circle represents the number of participants that have had that experience. The horizontal timeline represents how recently they have had the experience, with the most recent at the right.

Individually the findings indicate that the instruction they received in their K-8 Math Methods course had the strongest influence on their perceptions and plans to integrate an adaptive learning program in their future classroom. Participants noted that they were unaware of the breadth of adaptive learning programs available, the various options for implementing an adaptive learning program in their classroom, and the features available to teachers. All of this information that emerged from the archived journals and interviews could be explained by the fact that this was most likely the first experience the participants had looking at these programs 
from the perspective of a teacher. Prior to receiving this instruction, all of their experiences involved using these programs as students. The instruction changed their perceptions by making them aware of the different programs available and the ways in which they could be used in the classroom.

\section{Theme 1 - Type of Program and Implementation}

The first theme that emerged relating to experiences was: The type of program used and the way in which it was implemented has a strong influence on perceptions and plans for implementation. This theme emerged from three sub-themes: program design, implementation methods, and role of the teacher.

\section{Program Design}

The participants had a variety of experiences with different adaptive learning programs. Based on these experiences they clearly identified features that they liked and disliked about the various programs and they recognize all adaptive learning programs are not the same. They specifically mentioned items such as:

Nigel (Journal): I enjoyed using Khan Academy more than My Math Lab because I just liked being able to see my progress.

Kiya (Journal): From what I remember about Accelerated Math, it doesn't have nearly as many features as IXL.

Jasmine (Journal): Khan Academy's layout and pace is somewhat confusing for me. I mostly just concentrate on the number of skills that I have mastered. Otherwise its layout is very jumbled and all over the place.

Their experiences with different adaptive learning programs influenced their overall perceptions about them as well as their plans to integrate them in their future classroom. The participants recognized that they have a choice about which programs to use and that some might be more beneficial for teachers and students than others.

\section{Implementation Methods}

This particular sub-theme was prevalent across the archived journal data as well as the interviews. All of the participants had experiences with different implementation methods. They used them in different ways as students and learned about different implementation methods as a part of the classroom instruction they received. These experiences influenced their perception that adaptive learning programs should be used to supplement instruction. The data indicated that using an adaptive learning program as the primary curriculum is not something they plan to do in their future classroom because they do not want to give up control. Below are a few quotes that support their perceptions and plans for integrating in their future classrooms:

Brittany (Journal): I would use the adaptive learning program as a supplemental instruction. I would like to still be in control of how the students are learning and knowing 
where they are at with their learning. I would use the program to give the students who need it an extra challenge while the students who are struggling some extra practice as needed.

Adrien (Journal): Supplementary, because I do not want the students to be dependent on it. If it's fully integrated, I think it takes the fun out of the teaching.

\section{Teacher Support}

Participants had negative experiences with how much teacher support was being provided to them or to the students they were observing. These experiences influenced their plans for the level of support they plan to provide students. Many participants felt like they were working in isolation and did not have someone present to ask questions, as shown by the following quotes:

Bridget (Interview): ... my teacher was never like helpful, so I had to watch like the helpful videos which weren't all that helpful to me.

Madilyn (Journal): Working in isolation was difficult because if you didn't know the problem there was no one around to ask for help.

When participants had positive experiences with the type of program, the way it was implemented, and the level of teacher support, their perceptions of adaptive learning programs were more positive and their plans to integrate in their future classroom increased. Conversely, when they had negative experiences, their perceptions became negative and they were less likely to plan to integrate in their future classroom. This theme indicated that the participants will be more selective in choosing a program, they will use it to supplement their instruction, and they will provide higher levels of teacher support to their students than they received.

\section{Theme 2 - Instruction as a Turning Point}

The second theme that emerged relating to experiences was: They have limited experiences using adaptive learning programs as teachers, thus the instruction they received was a turning point. As indicated in the experiences explanation in the previous section, the participants had four distinct experiences with adaptive learning programs. Of those four experiences, two of them involved using adaptive learning programs as students, and two of them involved learning about using adaptive learning programs as a teacher. When comparing those four experiences, the majority of the time was spent using adaptive learning programs as students. The specific experiences that involved learning about adaptive learning programs as a teacher involved approximately $3 \mathrm{hr}$ of classroom instruction in their K-8 Math Methods course for all 17 participants and a very limited amount of time for 10 participants during their classroom field experiences.

The findings in the archived journals and interviews support this theme of having limited experiences, especially from a teacher's perspective. Several of the participants recognized this, and examples are provided below: 
Bradley (Interview): Well, it let me know they're a lot more available than I realize. And, also having not used them growing up I think it gave me a lot of better understanding of them as far as using them as a teacher as opposed to using them as a student.

Bridget (Interview): Well, I hadn't known there was all these different ones, so I got exposed to new ones, and I didn't realize that you could like sign your school up and sign up as a teacher, so that was cool to see like you could go on, you could log in to your class, you could track students, so that was cool to see new features from like the teacher's perspective rather than just being a student and doing it.

This data indicates that the participants recognize they have limited experiences working with adaptive learning programs as teachers. The specific experience that played the primary role in shaping this theme was the learning opportunities they received as a part of the instructional unit on adaptive learning programs in their K-8 Math Methods course. This was the first time the participants were exposed to the breadth of programs available and the first time they explored the features specifically available to teachers such as tracking student progress and assigning specific mathematics skills to students. Their experience learning about adaptive learning programs as teachers proved to be a turning point in their perceptions and plans to integrate in their future classroom. Prior to receiving instruction, their perceptions were more negative and they were less likely to use an adaptive learning program in their future classroom. After receiving instruction, their perceptions became more positive and their plans to use an adaptive learning program in their future classroom increased.

\section{Discussion}

The findings indicate participants believe adaptive learning programs are beneficial for students, but more importantly they recognize that they play an important role in how beneficial this particular technology can be. These findings align with the literature on teachers' plans to use adaptive learning programs. In a large-scale study, Dynarski et al. (2007) found that $86 \%$ of the teachers indicated they would use the adaptive learning program the following school year, and $24 \%$ said they would use it more often. This data does not necessarily indicate that participants perceive adaptive learning programs as being beneficial for students, although one would hope this is their rationale for planning to use an adaptive learning program in their future classroom.

Participants specifically mentioned that they enjoyed features of adaptive learning programs such as receiving immediate feedback, being able to work at their own pace, and personalizing the content for themselves and their students. This is closely aligned with the literature as well. There are a number of studies that have identified these as benefits of adaptive learning programs (Gross \& Duhon, 2013, Nguyen et al., 2006; Ysseldyke et al., 2003). Participants also noted other benefits for students associated with adaptive learning programs such as providing different instructional approaches and using instructional time efficiently. Again, these features align with the literature as well (Koedinger, McLaughlin, and Heffernan, 2010).

In addition to the positive features noted by participants, they also recognized that these programs are not perfect and there are drawbacks to using them. Participants highlighted things such as Internet issues, flaws in how the programs were designed, and cost. Several studies have identified these as barriers as well (Clark \& Whetstone, 2014; De Witte \& Rogge, 2014; Shih et al., 2012). The drawbacks noted by participates were much fewer than the positive features 
mentioned and thus led to the overall perception that adaptive learning programs are beneficial for students.

The findings also indicate that the participants had limited experiences using and learning about adaptive learning programs as teachers, but the experiences they did have had a strong influence on their perceptions and plans to integrate. Specifically, the instruction they received during their K-8 Math Methods course proved to be the turning point. It is safe to assume that increasing the number of experiences learning about adaptive learning programs as a teacher would be beneficial for preservice teachers. This particular finding is significant because we know that providing preservice teachers with adequate experiences using technology is important (AMTE, 2015; CAEP, 2013; National Education Technology Plan, 2016, Tondeura et al, 2012). Based on this finding, preservice teacher education programs should provide students with instruction specifically on adaptive learning programs.

Additionally, something that did not show up in the data, but was noted in the literature, is worth mentioning. The literature attributes some of the interest and growth of adaptive learning programs to the ability to capture learning analytics (Johnson et al., 2015). Adaptive learning programs can be used by teachers to make informed instructional decisions, by students for selfregulation, by administrators to support and justify expenditures, by researchers to analyze effectiveness, and by parents to stay informed of the child's educational progress (Johnson et al., 2014; Oxman \& Wong, 2014; Murphy et al., 2014). Despite these potential benefits, the majority of participants in this study did not recognize learning analytics as a key feature or benefit of adaptive learning programs. This can possibly be attributed to their lack of experience to using these programs as teachers and provides further evidence for the importance of providing preservice teachers with adequate experiences in their teacher preparation programs.

\section{Recommendations}

This study sheds light on the importance of spending time teaching students about adaptive learning programs in their teacher preparation courses. If preservice teachers are not given adequate opportunities to learn about technologies such as adaptive learning programs, their perceptions of those programs will be based on their usage as a K-12 student or college student. If these experiences are negative or limited, many preservice teachers may not be as apt to integrate the technology, or they may not be equipped to integrate it effectively. In addition, as technologies such as adaptive learning programs continue to evolve and become more sophisticated, it is important to show preservice teachers the features that exist and the pedagogical approaches that can be used. Teaching preservice teachers about adaptive learning programs should be a part of teacher education programs.

Additional research on this topic should be explored as well. Specifically, a longitudinal study that involves these same participants could be conducted to further explore their perceptions, how their perceptions continue to evolve, and how additional experiences influence their perceptions. More information could be gathered and analyzed to gain a better understanding of how perceptions change over time. This information could be valuable in gaining more insight into the influence of their experiences as well.

In addition, research on the specific experiences that influence perceptions and plans for integration could be conducted. This study explored the participants' experiences as a whole, but it did not take an in-depth look at what was involved in each of those experiences. For 
example, studies to determine what the best instructional interventions are for preparing preservice teachers to integrate adaptive learning programs could be conducted. Alternatively, a study that looks at what type of classroom field experiences are the most beneficial for preparing preservice teachers to integrate adaptive learning programs has the potential to be beneficial.

\section{Conclusion}

The findings from this study indicate that the participating preservice teachers plan to integrate this technology in their future K-8 mathematics classroom. The participating preservice teachers perceive adaptive learning programs to be beneficial for students, and they recognize they have many decisions to make regarding what adaptive learning programs are used and how they are integrated into the classroom. Providing preservice teachers with information on the types of programs available and the myriad of features available will help them be able to make these decisions. It is likely that the use of adaptive learning programs in the K-8 mathematics classroom will continue to increase. Thus, it is important to continue to make a concerted effort to prepare preservice teachers to use these programs effectively.

\section{References}

Albee, J. J. (2003). A study of preservice elementary teachers' technology skill preparedness and examples of how it can be increased. Journal of Technology and Teacher Education, 11(1), 53-71.

Association of Mathematics Teacher Educators on Technology (AMTE). (2015, November). Position of the Association of Mathematics Teacher Educators on Technology. Retrieved from https://amte.net/sites/default/files/technologypositionstatement-nov2015.pdf

Beal, C. R., Cohen, P. R., \& Woolf, B. P. (2010). Evaluation of AnimalWatch: An intelligent tutoring system for arithmetic and fractions. Journal of Interactive Online Learning, 9(1), 64-77.

Bochniak, J. S. (2014). The effectiveness of computer-aided instruction on math fact fluency. (Doctoral dissertation). Retrieved from http://scholarworks.waldenu.edu/

Brahier, D. J. (2013). Teaching secondary and middle school mathematics. Boston, Massachusetts. Pearson.

Braun, V., \& Clark, V. (2006). Using thematic analysis in psychology. Qualitative Research in Psychology, 3(2), 77-101.

Chai, C. S., Hwee, J., Koh, L., \& Tsai, C.-C. (2010). Facilitating Preservice Teachers' Development of Technological, Pedagogical, and Content Knowledge (TPACK). Educational Technology \& Society, 13(4), 63-73.

Cheung, A. C. K., \& Slavin, R. E. (2013). The effectiveness of educational technology applications for enhancing mathematics achievement in K-12 classrooms: A metaanalysis. Educational Research Review, 9, 88-113.

Clark, A. K., \& Whetstone, P. (2014). The Impact of an online tutoring program on mathematics achievement. The Journal of Educational Research, 107(6), 462-466. 
Council for the Accreditation of Educator Preparation (CAEP). (2013). 2013 CAEP Standards. Retrieved from http://www.caepnet.org/standards/introduction

Creswell, J. W. (2009). Research design: Qualitative, quantitative, and mixed method approaches (3rd ed.). Thousand Oaks, CA: Sage.

Davis, N., Preston, C., \& Sahin, I. (2009). ICT Teacher Training: Evidence for Multilevel Evaluation from a National Initiative. British Journal of Educational Technology, 40(1), 135-148.

Denzin, N. K. (1978). The research act: A theoretical introduction to sociological methods. New York: McGraw Hill.

De Witte, K., \& Rogge, N. (2014). Does ICT matter for effectiveness and efficiency in mathematics education? Computers and Education, 75, 173-184. doi: doi.org/10.1016/j.compedu.2014.02.012

Dynarski, M., Agodini, R., Heaviside, S., Novak, T., Carey, N., \& Campuzano, L. (2007). Effectiveness of reading and mathematics software products: Findings from the first student cohort. (NCEE 2007-4005). Washington, DC: National Center for Education Evaluation and Regional Assistance, Institute of Education Sciences, U.S. Department of Education.

Ertmer, P. A. (2005). Teacher pedagogical beliefs: The final frontier in our quest for technology integration? Educational Technology Research \& Development, 53(4), 25-39.

Eyyam, R., \& Yaratan, H. S. (2014). Impact of use of technology in mathematics lessons on student achievement and attitudes. Social Behavior \& Personality: An International Journal, 4231-42.

Gross, T. J., \& Duhon, G. (2013). Evaluation of Computer-Assisted Instruction for Math Accuracy Intervention. Journal of Applied School Psychology, 29, 246-261. http://doi.org/10.1080/15377903.2013.810127

Hanover Research (2014). Emerging and future trends in K-12 education. Hanover Research, (October), 1-30. Retrieved from http://www.hanoverresearch.com/media/Emergingand-Future-Trends-in-K-12-Education-1.pdf

Hennessy, S., Ruthven, K., \& Brindley, S. (2005). Teacher perspectives on integrating ICT into subject teaching: commitment, constraints, caution, and change. Journal of Curriculum Studies, 37(2), 155-192. http://doi.org/10.1080/0022027032000276961

Imbimbo, J. (2003). The voice of the new teacher. Washington, DC: Public Education Network.

International Society for Technology in Education [ISTE]. (2016). ISTE Standards for Administrators. Retrieved from http://www.iste.org/standards/standards-foradministrators

Johnson, L., Adams Becker, S., Estrada, V., \& Freeman, A. (2015). NMC Horizon Report: 2015 K12 Edition. Retrieved from http://www.nmc.org/publication/nmc-horizon-report-2015k-12-edition/

Kim, C., Kim, M. K., Lee, C., Spector, J. M., \& DeMeester, K. (2013). Teacher beliefs and technology integration. Teaching and Teacher Education, 29(1), 76-85. http://doi.org/10.1016/j.tate.2012.08.005

King, N., \& Horrocks, C. (2010). Interviews in qualitative research. Los Angeles, CA: Sage. 
Klinkenberg, S., Straatemeier, M., \& Van Der Maas, H. L. J. (2011). Computer adaptive practice of maths ability using a new item response model for on the fly ability and difficulty estimation. Computers and Education, 57(2), 1813-1824.

Koedinger, K. R., McLaughlin, E. A., \& Heffernan, N. T. (2010). A quasi-experimental evaluation of an on-line formative assessment and tutoring system. Journal of Educational Computing Research, 43(4), 489-510.

Kulik, J. A. (2003). Effects of using instructional technology in elementary and secondary schools: What controlled evaluation studies say final report. Science and Technology, 45(May), 82.

Lee, H., \& Hollebrands, K. (2008). Preparing to teach mathematics with technology: An integrated approach to developing technological pedagogical content knowledge. Contemporary Issues in Technology and Teacher Education, 8(4), 326-341. Retrieved from http://www.editlib.org/p/28191

Liao, Y. K. C. (2007). Effects of computer-assisted instruction on students' achievement in Taiwan: A meta-analysis. Computers and Education, 48(2), 216-233. doi: doi.org/10.1016/j.compedu.2004.12.005

Lincoln, Y. S., \& Guba, E. G. (1985). Naturalistic inquiry. Beverly Hills, CA: Sage.

Marshall, C., \& Rossman, G. B. (2016). Designing qualitative research (6th ed.). Thousand Oaks, CA: Sage.

Merriam, S. B. (2009). Qualitative research: A guide to design and implementation. San Francisco, CA: Jossey-Bass.

Merriam, S. B., \& Tisdell, E. J. (2016). Qualitative research: A guide to design and implementation (4th ed.). San Francisco, CA: Jossey-Bass.

Murphy, R., Gallagher, L., Krumm, A., Mislevy, J., \& Hafter, A. (2014). Research on the Use of Khan Academy in Schools. Retrieved from SRI Education web site: http://www.sri.com/sites/default/files/publications/khan-academy-implementationreport-2014-04-15.pdf

National Council of Teachers of Mathematics (NCTM). (2011, October). Technology in teaching and learning mathematics: A position of the National Council of Teachers of Mathematics. Retrieved from http://www.nctm.org/Standards-and-Positions/PositionStatements/Strategic-Use-of-Technology-in-Teaching-and-Learning-Mathematics/

National Council of Teachers of Mathematics (NCTM). (2014). Principles to actions: Ensuring mathematical success for all. Reston, VA: National Council of Teachers of Mathematics.

National Mathematics Advisory Panel. (2008). Foundations for success: The final report of the National Mathematics Advisory Panel. U.S. Department of Education.

Nguyen, D. M., Hsieh, Y.-C., \& Allen, G. D. (2006). The impact of web-based assessment and practice on students' mathematics learning attitudes. Journal of Computers in Mathematics and Science Teaching, 25(3), 251-279.

Niess, M. L. (2005). Preparing teachers to teach science and mathematics with technology: Developing a technology pedagogical content knowledge. Teaching and Teacher Education. http://doi.org/10.1016/j.tate.2005.03.006

Ojose, B. (2009). Promising practice of technology integration in math and science instruction: A case of California Charter High School. International Education Studies, 2(3), 3. 
Oxman, S., \& Wong, W. (2014). White paper: Adaptive learning systems. DV X Innovations DeVry Education Group.

Ozel, S., Yetkiner, Z. E., \& Capraro, R. M. (2008). Technology in K-12 mathematics classrooms. School Science and Mathematics, 108(2), 80. doi: doi.org/10.1111/j.19498594.2008.tb17807.x

Pane, J. F., Griffin, B. A., McCaffrey, D. F., \& Karam, R. (2013). Effectiveness of Cognitive Tutor Algebra I at Scale. Educational Evaluation and Policy Analysis, 36(2), 127-144. doi: doi.org/10.3102/0162373713507480

Schacter, J. (1999). The impact of education technology on student achievement: What the most current research has to say. Milken Exchange on Education Technology, 1-13.

Shih, S. C., Kuo, B. C., \& Liu, Y. L. (2012). Adaptively ubiquitous learning in campus math path. Educational Technology and Society, 15(2), 298-308.

Sutton, S. R. (2011). The preservice technology training experiences of novice teachers. Journal of Digital Learning in Teacher Education, 28(1), 39-47. http://doi.org/10.1080/21532974.2011.10784678

The White House ConnectED Initiative. (2013, June 6). ConnectED Initiative. Retrieved from https://www.whitehouse.gov/issues/education/k-12/connected

Tondeur, J., Van Braak, J., Sang, G., Voogt, J., Fisser, P., \& Ottenbreit-Leftwich, A. (2012). Preparing pre-service teachers to integrate technology in education: A synthesis of qualitative evidence. Computers and Education, 59(1), 134-144. http://doi.org/10.1016/j.compedu.2011.10.009

U.S. Department of Education Office of Educational Technology. (2016). Future ready learning: Reimagining the role of technology in education. 2016 National Education Technology Plan. Washington, D.C.

Weaver, G. (2000). An examination of the national educational longitudinal study (NLES:88) database to probe the correlation between computer use in school and improvement in test scores. Journal of Science Education and Technology, 9(2), 121-133. doi: doi.org/10.1023/A:1009457603800

Wenglinsky, H. (1998). Does it compute? The relationship between educational technology and student achievement in mathematics. Retrieved from Educational Testing Service Policy Information Center web site: https://www.ets.org/research/policy_research_reports/ pic-technology

Ysseldyke, J., Spicuzza, R., Kosciolek, S., \& Boys, C. (2003). Effects of a learning information system on mathematics achievement and classroom structure. The Journal of Educational Research, 96(3), 163-173.

Zhang, M., Trussell, R. P., Gallegos, B., \& Asam, R. R. (2015). Using math apps for improving student learning: An exploratory study in an inclusive fourth grade classroom. TechTrends, 59(2), 32-39. http://doi.org/10.1007/s11528-015-0837-y 